Jorge Martín-Márquez, Jesús Ma. Rincón, Maximina Romero, Effect of microstructure on mechanical properties of porcelain stoneware. Journal of the European Ceramic Society, Volume 30, Issue 15, November 2010, Pages 3063-3069; doi:10.1016/j.jeurceramsoc.2010.07.015

\title{
Effect of microstructure on mechanical properties of porcelain stoneware
}

Jorge Martín-Márquez, Jesús Ma. Rincón, Maximina Romero

Group of Glass and Ceramic Materials, Department of Building Construction Systems, Eduardo

Torroja Institute for Construction Sciences-CSIC, Serrano Galvache 4, 28033 Madrid, Spain

\begin{abstract}
This work examines the effect of microstructure (aspect ratio of mullite crystals and proportion of crystalline and amorphous phases) as well as different physical features (bulk density, closed and open porosity and absolute density) on the mechanical properties of a standard porcelain stoneware composition (50\% kaolinitic clay, 40\% feldspar and 10\% quartz) fired in the $1200-1300{ }^{\circ} \mathrm{C}$ temperature interval using a fast firing schedule. The mechanical behaviour was evaluated in terms of bending strength, Vickers microhardness, fracture toughness and Young's modulus. After viewing the results, it can be concluded that increased $\sigma f, H v$ and $E$ values were mainly due to open porosity, percentage of mullite phase and morphology of secondary mullite needles, whereas closed porosity and quartz particles have no influence on these properties.
\end{abstract}

\section{Keywords}

Mullite; Porcelain stoneware; Mechanical properties; Traditional ceramics; Microstructure-final

\section{Introduction}

Porcelain stoneware tile is a ceramic building material with high bending strength and abrasion resistance. It is generally used in pavements, as wall covering and as ventilated facades. In recent years, it has experienced the greatest increase in production and sales of all ceramic building materials.

Porcelains typically have a triaxial composition comprised of about $50 \%$ clay, $25 \%$ flux and $25 \%$ filler. Fired bodies containing these three components result in a grain and bond microstructure, which has large grains or filler (usually quartz) held together by a finer bond or matrix comprised of mullite crystals and a glassy phase. In relation to its raw material composition (clay, quartz and feldspar), porcelain stoneware is considered to be a triaxial porcelain material. However, porcelain stoneware tile is produced using a fast firing schedule (temperature rates up to $60^{\circ} \mathrm{C} / \mathrm{min}$ ), in which the tiles are inside the furnace no longer than 60 90 min. This is in contrast to the lengthy (several hours) process employed in porcelain 
Jorge Martín-Márquez, Jesús Ma. Rincón, Maximina Romero, Effect of microstructure on mechanical properties of porcelain stoneware. Journal of the European Ceramic Society, Volume 30, Issue 15, November 2010, Pages 3063-3069; doi:10.1016/j.jeurceramsoc.2010.07.015

manufacture. Consequently, the microstructure of porcelain and porcelain stoneware is different because the firing process affects the ratio of crystalline to amorphous phases in the end products. Mullite and glass are the major phases in porcelain. In porcelain stoneware tile, quartz is more abundant than mullite.

Concerning mechanical properties of porcelain bodies, several theories have evolved, which assume that strength can be attributed to factors such as mullite content and morphology, as well as quartz particles and porosity.

Various studies have shown that the strength of a porcelain body is related to felt-like interlocking of fine mullite needles. Consequently, the strength increases with increasing mullite content. This assumption was first proposed by Zoellner. ${ }^{1}$ However, at times, the beneficial effect of mullite content is not evident. Several researchers have not found a clear relationship between mullite content and bending strength $2.3^{\text {and }} 4$ and a recent study on the influence of composition on mechanical behaviour of porcelain tile $e^{5}$ has shown that mullite significantly worsen the fracture energy, which invalidates the mullite hypothesis as a mechanism to strengthen the porcelain tile.

The function of quartz in the strength of a porcelain body has also been taken into consideration. Some authors suggest that the mismatch in the thermal expansion coefficient, $\alpha$, between quartz particles $\left(\alpha \approx 15-26 \times 10^{-6}{ }^{\circ} \mathrm{C}^{-1}\right)$ and the silicate glass matrix $(\alpha \approx 5$ $8 \times 10^{-6}{ }^{\circ} \mathrm{C}^{-1}$ ) generate a compressive stress on the matrix, which leads to strength reinforcement in the porcelain bodies. According to this theory, a higher residual quartz content results in higher strength. Nevertheless, other researchers have reported that such a relationship is not very clear and the dependence even seems to be the opposite. $4^{\text {and }} 6$ MattyasovszkyZsolnay ${ }^{7}$ reported that the bending strength of porcelain bodies is strongly dependent on quartz particle size and that to assure a suitable compressive prestress to the vitreous phase, the added quartz particles must be within the $10-30 \mu \mathrm{m}$ range. If the quartz grains are very fine, they are highly dissolved in the glass matrix, whereas if grains are too coarse, they induce crack generation. More recently, other authors have supported this idea and reported similar results in silica and sanitary porcelains. 2,8 and 9

In addition, other studies have also found evidence of the influence of the microstructure of porcelain bodies on the bending strength. Thus, several authors have suggested a close relationship between the amount of glassy phase present in the fired body and bending strength $2{ }^{\text {and }} 4$ or fracture toughness. ${ }^{10}$ In contrast, other studies have claimed that an increase in the vitreous phase decreases the mechanical resistance of porcelain bodies. ${ }^{6}$ 
Jorge Martín-Márquez, Jesús Ma. Rincón, Maximina Romero, Effect of microstructure on mechanical properties of porcelain stoneware. Journal of the European Ceramic Society, Volume 30, Issue 15, November 2010, Pages 3063-3069; doi:10.1016/j.jeurceramsoc.2010.07.015

Porosity has also been shown to affect mechanical properties. It was reported that the Young's modulus decreases with increasing porosity $10^{\text {and }} 11$ and at equivalent porosities, specimens with small pores were found to have a higher Young's modulus than specimens with large pores. ${ }^{12}$

As mentioned above, because of the fast firing process, the microstructure shown by porcelain and porcelain stoneware is rather different. The effect of microstructure on the technological properties of porcelain stoneware products has been studied over the past few years and, similar to porcelain, the effect of microstructure on mechanical properties is not well established. Thus, several studies suggest that internal porosity is the main factor affecting Young's modulus and the flexural strength of stoneware.13 $14^{\text {and }} 15$ Some authors claim that mechanical improvement is mainly influenced by the stresses set up in the glassy matrix, which are induced by the quartz grains rather than the amount or size of mullite. $16^{\text {and }} 17$ Other researchers maintain that mullite content plays a major role in resistance to deep abrasion, owing to both its hardness and a toughening mechanism originating from differences in thermal expansion and elastic modulus between the glassy and mullite phases, which induce compression at grain boundaries 18 and 19 and toughness of porcelain stoneware increases as the quantity of crystallising mullite increases. ${ }^{20}$ Finally, it has been also suggested that the mechanical characteristics of stoneware increase with decreasing percentage of the glassy phase. ${ }^{21}$ However, although much effort has been made to enhance the mechanical properties of porcelain stoneware tiles, the effect of mullite crystal morphology has not received significant consideration.

The aim of this work is to study the evolution of mechanical properties on firing in porcelain stoneware and to establish the influence of microstructure, taking into consideration percentage, shape and size of mullite crystals. For this purpose, a standard porcelain stoneware body was fired between 1200 and $1300{ }^{\circ} \mathrm{C}$ using a fast firing process. The mechanical properties of the end products have been correlated with their physical and microstructural features, which have been determined in previous work. 22.23 and 24

\section{Materials and methods}

Raw materials used in the present investigation were kaolinitic clay and feldspar (provided by Compañía Europea de Arcillas, S.A. and designed as AR-2097-G and FC-100 respectively), and quartz sand (facilitated by IETcc, CSIC). Chemical composition, as determined by inductively coupled plasma optical emission spectroscopy (ICP-OES), and mineralogical 
Jorge Martín-Márquez, Jesús Ma. Rincón, Maximina Romero, Effect of microstructure on mechanical properties of porcelain stoneware. Journal of the European Ceramic Society, Volume 30, Issue 15, November 2010, Pages 3063-3069; doi:10.1016/j.jeurceramsoc.2010.07.015

composition determined by X-ray diffraction (XRD) are shown in Table 1. All the above materials were crushed, ground and finally powdered to $<160 \mu \mathrm{m}$ prior to further use.

Table 1. Chemical and mineralogical analyses of raw materials used in this work.

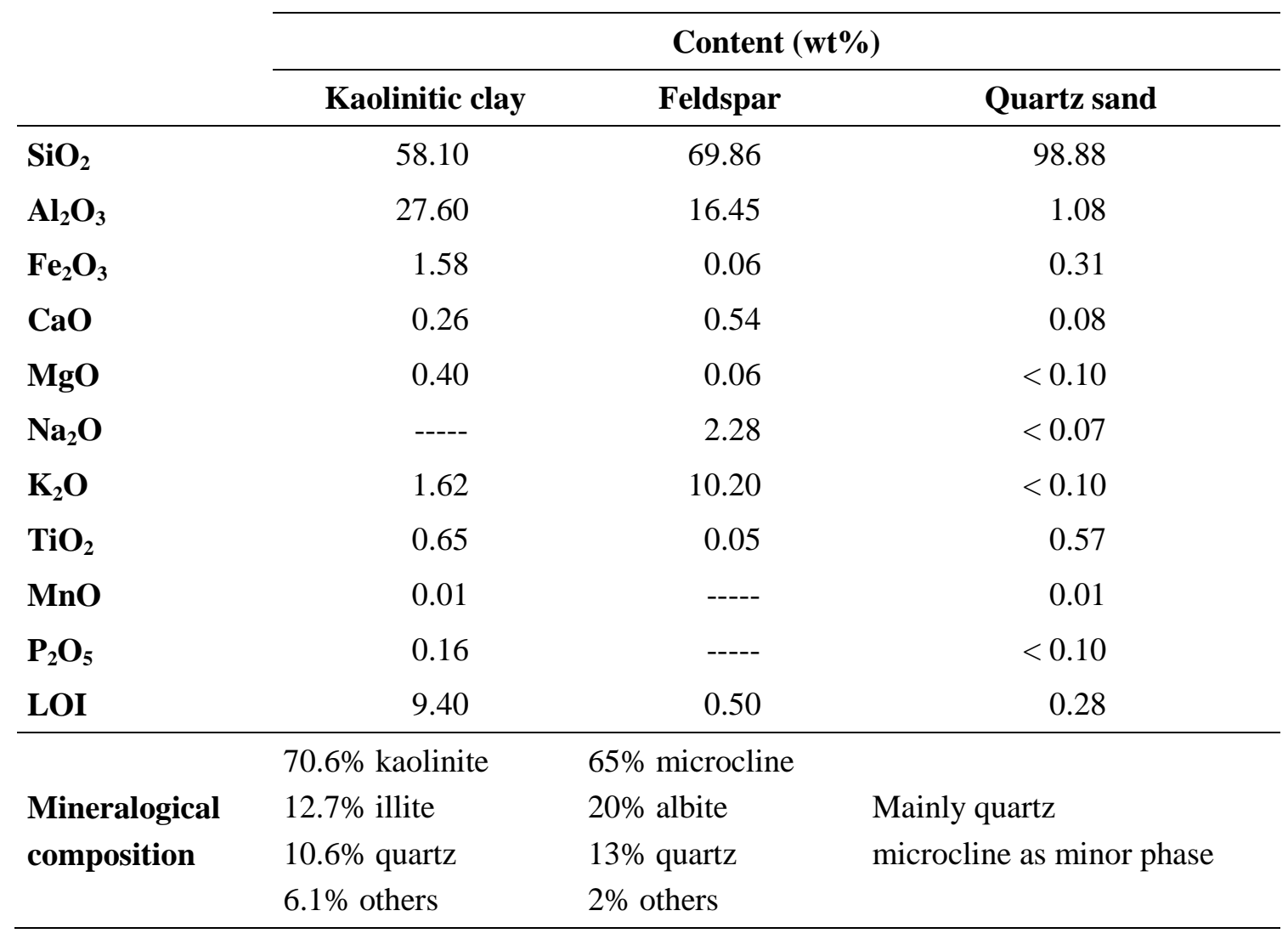

A standard porcelain stoneware composition was prepared by mixing 50\% kaolinitic clay, $40 \%$ feldspar and 10\% quartz. Batches (300 g each) were prepared by milling the constituents with distilled water (1:1) for $30 \mathrm{~min}$ in a planetary ball mill (TURBULA) using alumina balls as the grinding media. The resultant slurry was oven-dried overnight at $110^{\circ} \mathrm{C}$, powdered in a porcelain mortar and pestle, and sieved to pass -100 mesh $(150 \mu \mathrm{m})$. The resulting powder was moistened by spraying it with distilled water (6 wt $\%$ ) and was uniaxially pressed at $40 \mathrm{MPa}$ in a steel die. Discs of $20 \mathrm{~mm}$ diameter and $5 \mathrm{~mm}$ height were shaped from $3 \mathrm{~g}$ of powder. Square tiles $(30 \mathrm{~g}$ each) of $50 \mathrm{~mm} \times 50 \mathrm{~mm} \times 8 \mathrm{~mm}$ dimensions were prepared for bending strength measurements. After drying in an oven at $110{ }^{\circ} \mathrm{C}$, the compacts were placed on alumina rollers in an electric furnace and fired between 1200 and $1300{ }^{\circ} \mathrm{C}$, following a typical fast firing process used by the ceramic tile industry. The samples were heated for $\sim 30 \mathrm{~min}$ to the required 
Jorge Martín-Márquez, Jesús Ma. Rincón, Maximina Romero, Effect of microstructure on mechanical properties of porcelain stoneware. Journal of the European Ceramic Society, Volume 30, Issue 15, November 2010, Pages 3063-3069; doi:10.1016/j.jeurceramsoc.2010.07.015

temperature, soaked for $15 \mathrm{~min}$ and then cooled in the furnace at $50{ }^{\circ} \mathrm{C} / \mathrm{min}$ to room temperature. Because of the high fluxing agent content, stoneware bodies exhibited pyroplasticity when fired at temperatures higher than $1300{ }^{\circ} \mathrm{C}$, and thus it has not been feasible to correlate the microstructure of those specimens with their mechanical properties.

The bulk density, $B\left(\mathrm{~g} / \mathrm{cm}^{3}\right)$, and open porosity, $\varepsilon o(\%)$, were measured according to ASTM C373-88. The total porosity of the sample, $\varepsilon T(\%)$ is determined as $\varepsilon T=(1-B / A D)$, where $A D\left(\mathrm{~g} / \mathrm{cm}^{3}\right)$ is the absolute density of the sample, which was previously measured according to ASTM C329-88. The close porosity, $\varepsilon c(\%)$, is then calculated as the difference between $\varepsilon T$ and $\varepsilon o$.

The microstructure of fired specimens was examined by scanning electron microscopy (SEM, Philips XPERT microscope) using an accelerate voltage of $20 \mathrm{kV}$. For SEM observation, the specimens were $\mathrm{Au}-\mathrm{Pd}$ coated (Balzers SCD 050 sputter). The analysis of porosity evolution during firing was accomplished on samples polished to $1 \mu \mathrm{m}$ finish with diamond pastes after initial grinding with $\mathrm{SiC}$ powder. For analysis of phase assemblages and morphology, the fresh fracture surfaces were etched for 4 min in 15\% HF solution, washed ultrasonically with distilled water and ethylic alcohol, dried and subsequently Au-Pd coated.

Quantification of phases was carried out by Rietveld analysis. Finely powdered porcelain stoneware samples were mixed with $\sim 30 \%$ high purity calcined $\alpha-\mathrm{Al}_{2} \mathrm{O}_{3}$ as internal standard. The mixture was homogenized by hand milling for $5 \mathrm{~min}$ in an agate mortar with acetone. Powder diffraction patterns were collected at room temperature (Siemens D5000 ( $\mathrm{CuK}_{\alpha}$ radiation) diffractometer) working at $40 \mathrm{kV}$ and $30 \mathrm{~mA}$. Intensities were collected by step-scanning in the $10-70^{\circ}(2 \theta)$ range, with steps of $0.03^{\circ}$ and a counting time of $8 \mathrm{~s}$ for each step.

Bending strength, $\sigma f$, was measured according to UNE-EN 843-1 in an electronic universal tester (Servosis) on 10 test pieces of $50 \mathrm{~mm} \times 10 \mathrm{~mm} \times 8 \mathrm{~mm}$ by a three-point loading test with a span of $36 \mathrm{~mm}$ and a crosshead speed of $3 \mathrm{~mm} / \mathrm{min}$. Vickers microhardness, $H v$, and fracture toughness, KIC, measurements were performed using the indentation technique with a load of $1000 \mathrm{~g}$ for a dwell time of $15 \mathrm{~s}$ (Matsuzawa Hardness tester). Samples were ground with silicon carbide paper and then polished using 6, 3 and $1 \mu \mathrm{m}$ diamond pastes prior to measurement. For each case, an average of 10 measurements was taken. The cracks were measured immediately after indentation, thereby minimising any subcritical crack growth caused by residual stresses. Crack measurements were only made on indents that were well defined without chipping and 
Jorge Martín-Márquez, Jesús Ma. Rincón, Maximina Romero, Effect of microstructure on mechanical properties of porcelain stoneware. Journal of the European Ceramic Society, Volume 30, Issue 15, November 2010, Pages 3063-3069; doi:10.1016/j.jeurceramsoc.2010.07.015

for cracks that did not terminate at pores. Young's modulus, $E$, was measured by the resonance frequency method (Grindosonic analyser).

\section{Results and discussion}

Fig. 1 shows the variation of bending strength in porcelain stoneware as function of firing temperature in the $1200-1300{ }^{\circ} \mathrm{C}$ range. The value of $\sigma$ increases with firing temperature, reaching a maximum value at $1280{ }^{\circ} \mathrm{C}$. Above that temperature, firing leads to reduced strength. To better depict this behaviour, Fig. 2 shows the variation of bending strength as a function of different physical features of the fired bodies. It is noted that bending strength is not dependent on the closed porosity of the piece because porcelain stoneware samples fired at 1270 and $1300{ }^{\circ} \mathrm{C}$ show similar of values even though their closed porosity is very different. What does seem to have a positive effect on bending strength is the open porosity of the sample. Fig. 2 clearly shows that of increases at the $1200-1250{ }^{\circ} \mathrm{C}$ interval when a reduction in open porosity close to $40 \%$ occurs. However, the bending strength continues to increase in samples fired in the $1250-1270{ }^{\circ} \mathrm{C}$ range when the open porosity is almost constant, with an average value of $3.53 \%$. This result indicates that although bending strength is influenced by open porosity, it is not the only factor having an effect. Regarding the relationship between bending strength and density, there is a wide scattering of data in the representation of absolute density, whereas bulk density shows similar behaviour to open porosity, as these properties are directly related.

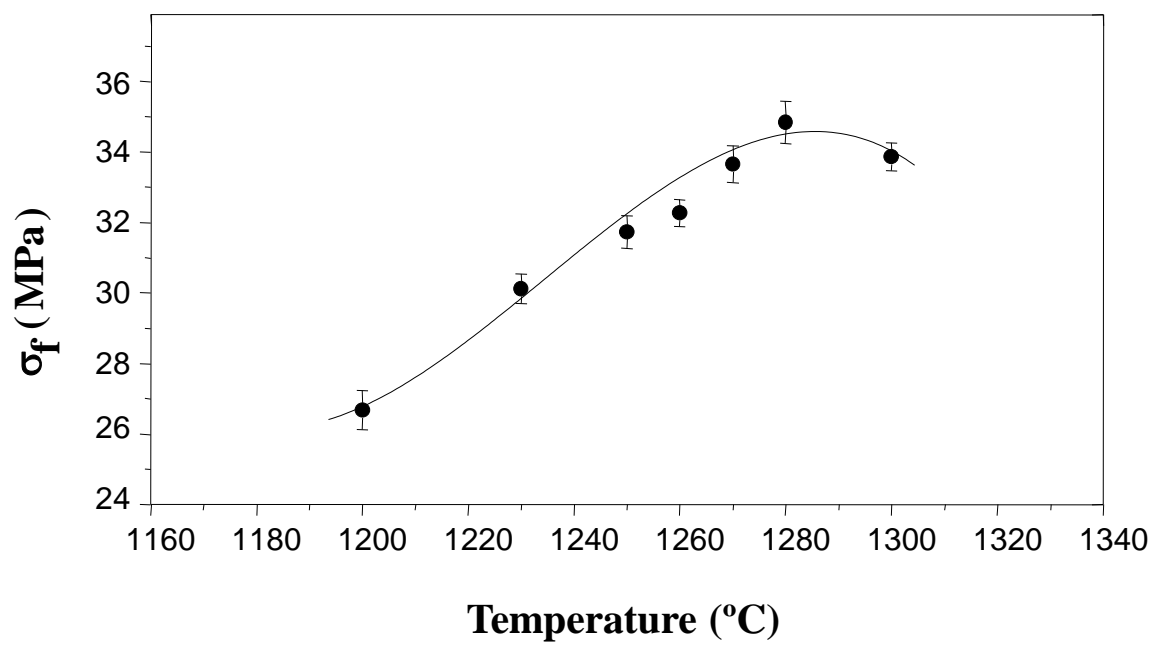

Fig. 1. Variation of bending strength in porcelain stoneware as a function of firing temperature in the $1200-1300{ }^{\circ} \mathrm{C}$ range. 
Jorge Martín-Márquez, Jesús Ma. Rincón, Maximina Romero, Effect of microstructure on mechanical properties of porcelain stoneware. Journal of the European Ceramic Society, Volume 30, Issue 15, November 2010, Pages 3063-3069; doi:10.1016/j.jeurceramsoc.2010.07.015

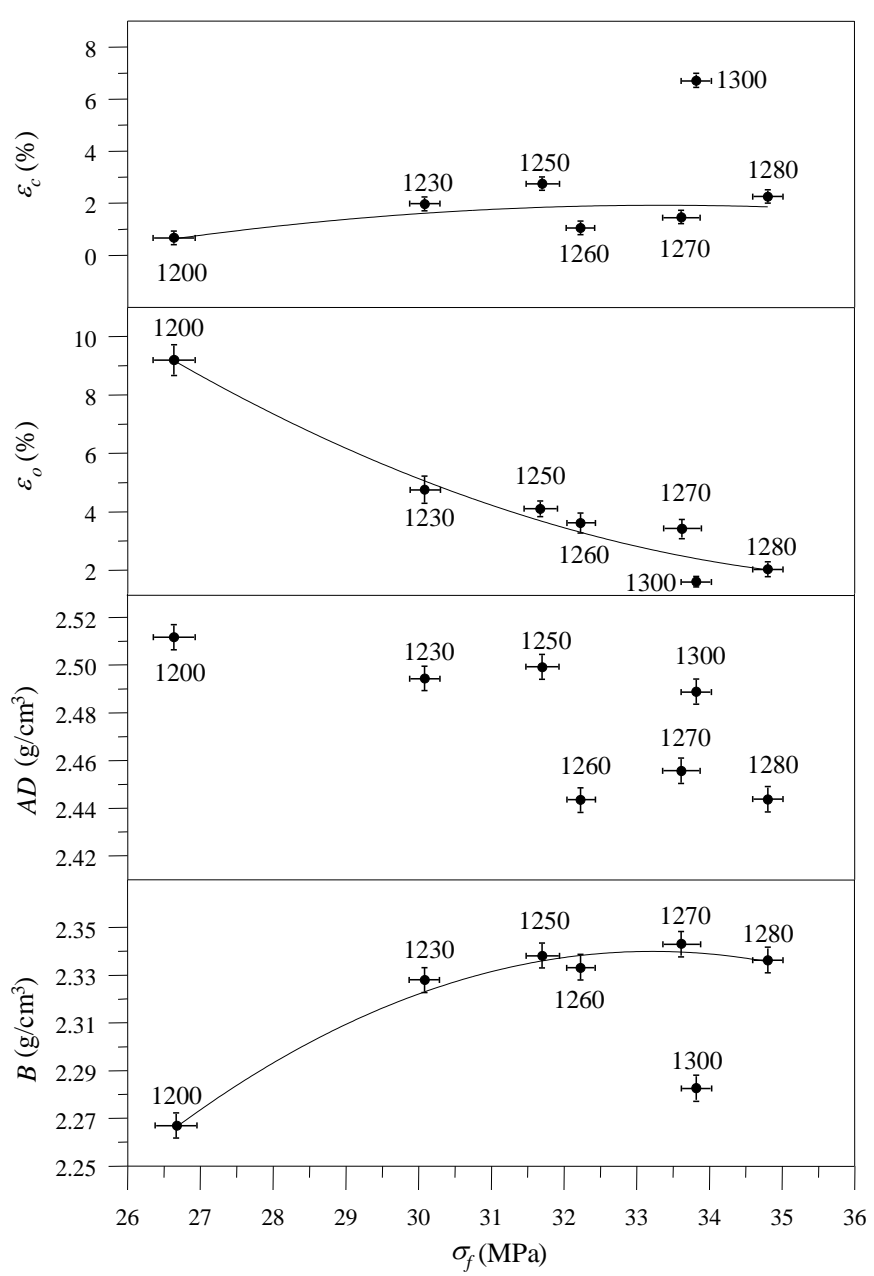

Fig. 2. Variation of bending strength as a function of different physical features of the fired porcelain stoneware (close porosity $(\varepsilon c)$, open porosity $(\varepsilon o)$, absolute density $(A D)$ and bulk density $(B))$.

Fig. 3 shows the variation of bending strength as a function of the contents of quartz, mullite and the glassy phase obtained by the Rietveld method. of increases in the $1200-1230{ }^{\circ} \mathrm{C}$ interval, in which the percentage of mullite increases nearly $20 \%$ and continues to increase in the $1230-1300{ }^{\circ} \mathrm{C}$ interval, when the mullite content is almost constant with an average value of $14.3 \%$. Although this result is consistent with the hypothesis of mullite, which suggests that higher mullite content results in greater bending strength, 1'18,19 and 20 it also suggests the existence of another factor having influence on the flexural strength of porcelain stoneware specimens. A similar trend is depicted by the glassy phase curve, which shows an enhancement of of in the $1200-1230^{\circ} \mathrm{C}$ interval, in which the percentage of the glassy phase increases about $7 \%$ and continues to increase in the $1230-1300{ }^{\circ} \mathrm{C}$ interval, where the glassy phase is roughly constant with an average value of $60 \%$. Concerning quartz particles, Fig. 3 shows how the 
Jorge Martín-Márquez, Jesús Ma. Rincón, Maximina Romero, Effect of microstructure on mechanical properties of porcelain stoneware. Journal of the European Ceramic Society, Volume 30, Issue 15, November 2010, Pages 3063-3069; doi:10.1016/j.jeurceramsoc.2010.07.015

percentage of this phase seems to have no influence on $\sigma f$. This is because bending strength increases in the $1230-1300{ }^{\circ} \mathrm{C}$ interval when quartz content is constant and even increases in the $1200-1230{ }^{\circ} \mathrm{C}$ interval when the percentage of quartz decreases. This result contradicts the prestressed theory, which proposes that quartz particles produce strong compressive stresses on the glassy phase with consequent mechanical property enhancement. In a recent study, De Noni et al. ${ }^{5}$ have found that quartz particles have a decisive contribution on increasing the fracture energy in porcelain tile, either by increasing the state of compressive residual stress in the glass matrix, or by promoting a combination of the mechanism of crack deflection and microcracking. However, the results are in good agreement with the results given by Maity and Sarkar ${ }^{25}$, which show that quartz particles have an adverse effect on the flexural strength of porcelain compositions.

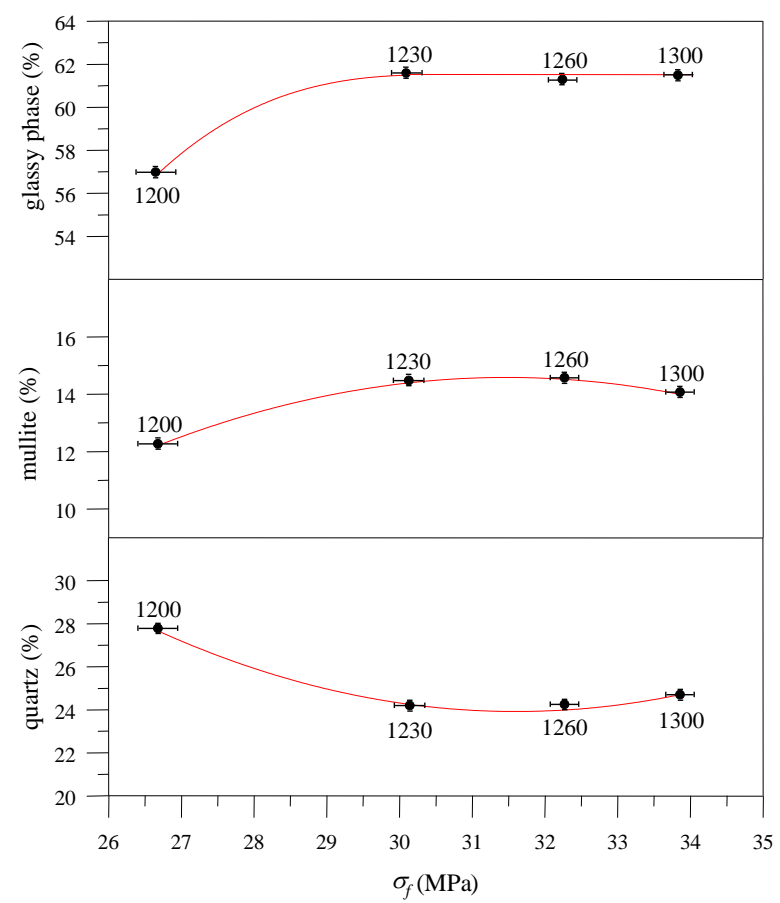

Fig. 3. Variation of bending strength in porcelain stoneware as a function of the contents of crystalline and glassy phases.

Fig. 4 depicts the variation of bending strength as a function of the aspect ratio showed by secondary mullite needles developed at the different firing temperatures. It can be seen that both factors are directly associated. $\sigma$ improves throughout the whole temperature interval when the aspect ratio increases from $7: 1$ at $1200{ }^{\circ} \mathrm{C}$ to $50: 1$ at $1300{ }^{\circ} \mathrm{C}$. Fig. 5 shows micrographs of porcelain stoneware specimens fired at different temperatures in the $1200-1300{ }^{\circ} \mathrm{C}$ interval. The increase in bending strength in Fig. 3 takes place at the $1230-1260{ }^{\circ} \mathrm{C}$ interval and concurs with 
Jorge Martín-Márquez, Jesús Ma. Rincón, Maximina Romero, Effect of microstructure on mechanical properties of porcelain stoneware. Journal of the European Ceramic Society, Volume 30, Issue 15, November 2010, Pages 3063-3069; doi:10.1016/j.jeurceramsoc.2010.07.015

the arrangement of Type III secondary mullite crystals to form clusters or packs of needles, as has been observed by the authors in previous work focused on the study of microstructural evolution during the firing of porcelain stoneware. ${ }^{24}$ Thus, at $1250{ }^{\circ} \mathrm{C}$, bigger mullite needles begin to appear that show a considerable growth in both longitudinal and axial axes. A detailed observation of this growth suggests that mullite fibres, with an aspect ratio $>30: 1$, join together and give rise to clusters or packs of needles.

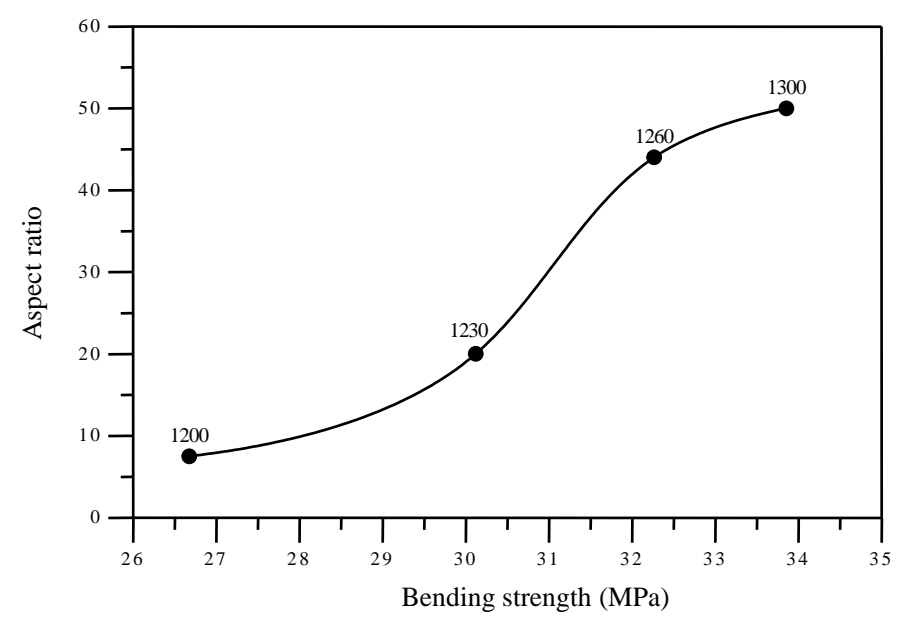

Fig. 4. Variation of bending strength in porcelain stoneware as a function of the aspect ratio shown by secondary mullite needles developed at different firing temperatures
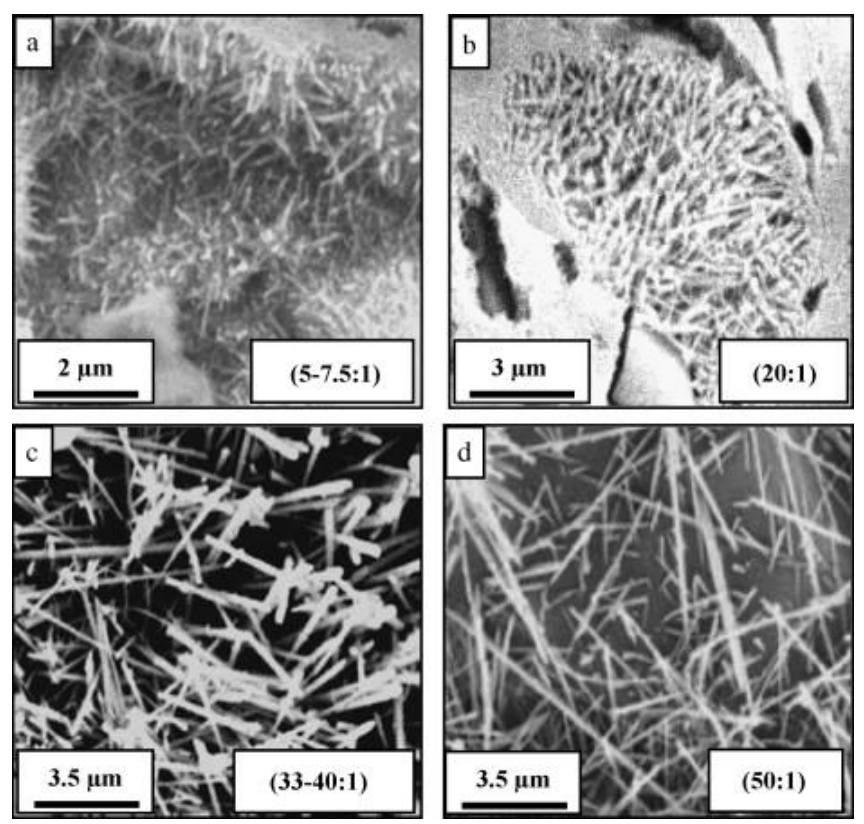

Fig. 5. SEM images of freshly fractured etched porcelain stoneware pellets fast fired at different temperatures. (a) $1200{ }^{\circ} \mathrm{C}$, (b) $1250{ }^{\circ} \mathrm{C}$, (c) $1260{ }^{\circ} \mathrm{C}$ and (d) $1300{ }^{\circ} \mathrm{C}$. 
Jorge Martín-Márquez, Jesús Ma. Rincón, Maximina Romero, Effect of microstructure on mechanical properties of porcelain stoneware. Journal of the European Ceramic Society, Volume 30, Issue 15, November 2010, Pages 3063-3069; doi:10.1016/j.jeurceramsoc.2010.07.015

After viewing the results showed in Fig. 1, Fig. 2, Fig. 3 and Fig. 4, it can be concluded that increased strength in the present porcelain stoneware composition was mainly due to open porosity, percentage of the mullite phase and morphology of secondary mullite needles. It is noteworthy that, although the influence of the first two factors has been referenced in earlier investigations of triaxial porcelain, there is no previous evidence of the importance of aspect ratio of mullite crystals on the mechanical properties of such materials.

Table 2 displays the values of the Vickers microhardness $(H v)$, Young's modulus $(E)$ and fracture toughness $(K I C)$ of porcelain stoneware samples after fast firing in the $1200-1300{ }^{\circ} \mathrm{C}$ interval. Fig. 6 and Fig. 7 depict the variation of Vickers microhardness and Young's modulus as function of different physical features and phase compositions of the fired bodies. It is noted that all curves show similar behaviour to bending strength curves, which indicates that these properties are related and that the factors responsible for $\sigma f$ increasing also govern Vickers microhardness and Young's modulus. It is remarkable that the body fast fired at $1300{ }^{\circ} \mathrm{C}$ shows the highest values of $E$ and also the maximum values of close and total porosity, which is in disagreement with the presumption that the Young's modulus decreases with increasing porosity. The Young's modulus-porosity correlation has been the subject of several investigations and numerous equations can be found in the literature. For example, the following dependence of $E$ on porosity $(P)$ has been proposed by Boccaccini and Boccaccini ${ }^{26}: E(P)=E_{0}\left(1-P^{2 / 3}\right) s$, where $E(P)$ and $E_{0}$ are the Young's modulus of the porous body and of the pore-free material respectively and $s$ is a factor depending on pore shape and orientation. Nevertheless, in complex multi-phase systems such as porcelain stoneware, the correlation with the proposed theoretical models is difficult to find out. ${ }^{14}$

Table 2. Mechanical properties of porcelain stoneware samples after fast firing in the $1200-1300{ }^{\circ} \mathrm{C}$ interval.

\begin{tabular}{rccc}
\cline { 2 - 4 } & $\boldsymbol{H}_{v}(\mathbf{G P a})$ & $\boldsymbol{E}(\mathbf{G P a})$ & $\boldsymbol{K}_{I C}\left(\mathbf{M P a} \cdot \mathbf{m}^{\mathbf{1} / \mathbf{2}}\right)$ \\
\hline $\mathbf{1 2 0 0}^{\circ} \mathbf{C}$ & 4.6 & 48 & 1.3 \\
$\mathbf{1 2 3 0}^{\circ} \mathbf{C}$ & 4.9 & 49 & 1.2 \\
$\mathbf{\mathbf { 1 2 5 0 } ^ { \circ } \mathbf { C }}$ & 5.3 & 61 & 1.3 \\
$\mathbf{1 2 6 0}^{\circ} \mathbf{C}$ & 5.2 & 61 & 1.2 \\
$\mathbf{1 2 7 0}^{\circ} \mathbf{C}$ & 5.3 & 61 & 1.4 \\
$\mathbf{1 2 8 0}^{\circ} \mathbf{C}$ & 5.7 & 57 & 1.3 \\
$\mathbf{1 3 0 0}^{\circ} \mathbf{C}$ & 5.5 & 65 & 1.4 \\
\hline
\end{tabular}


Jorge Martín-Márquez, Jesús Ma. Rincón, Maximina Romero, Effect of microstructure on mechanical properties of porcelain stoneware. Journal of the European Ceramic Society, Volume 30, Issue 15, November 2010, Pages 3063-3069; doi:10.1016/j.jeurceramsoc.2010.07.015

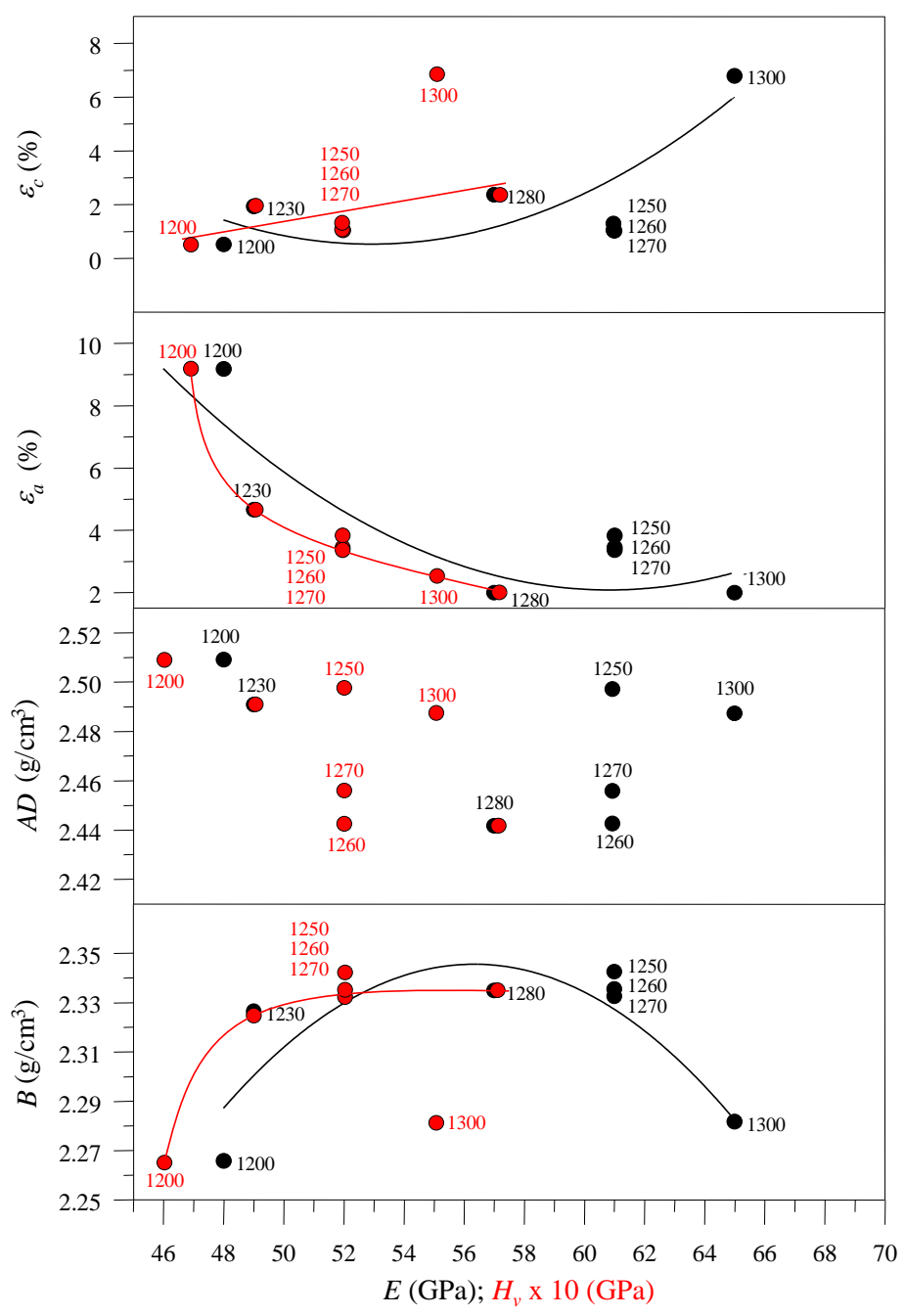

Fig. 6. Variation of Vickers microhardness and Young's modulus as a function of different physical features of the fired porcelain stoneware.

The increase found in $E$ with porosity can be explained by taking into account the aspect ratio of mullite needles, which at $1300{ }^{\circ} \mathrm{C}$ have reached their maximum length (50:1) and have growth inside the pores, leading to a strengthening of the porcelain stoneware body. Finally, in Table 2, it is noted that the fracture toughness remains constant in the $1200-1300{ }^{\circ} \mathrm{C}$ interval, with an average value of $1.3 \mathrm{MPa} \mathrm{m}^{1 / 2}$. This is independent of the firing temperature and, therefore, of the physical properties and microstructural features of the fired body. 
Jorge Martín-Márquez, Jesús Ma. Rincón, Maximina Romero, Effect of microstructure on mechanical properties of porcelain stoneware. Journal of the European Ceramic Society, Volume 30, Issue 15, November 2010, Pages 3063-3069; doi:10.1016/j.jeurceramsoc.2010.07.015

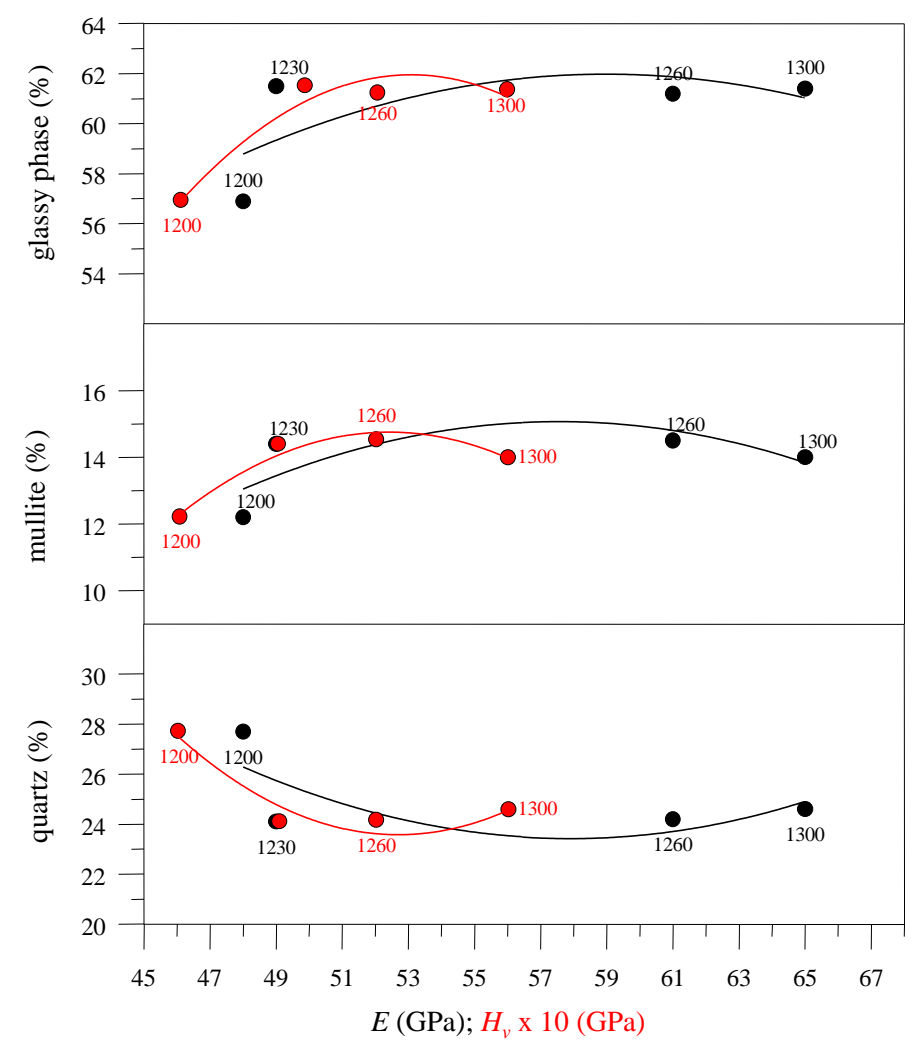

Fig. 7. Variation of Vickers microhardness and Young's modulus as a function of the contents of crystalline and glassy phases.

\section{Conclusions}

A mixture of $50 \%$ kaolinitic clay, $40 \%$ feldspar and $10 \%$ quartz was selected as a representative composition of commercial porcelain stoneware tiles produced via a fast firing process. After correlating different mechanical properties with several physical features and phase compositions, the following conclusions can be made:

1. Bending strength is not dependent on closed porosity, but is reliant on open porosity of the sample.

2. The results are consistent with the hypothesis of mullite, because higher mullite content results in greater bending strength and contradicts the prestressed theory because quartz particles have no influence on $\sigma$.

3. Bending strength is directly associated to the aspect ratio shown by secondary mullite needles. An increase in the aspect ratio of crystals was observed to increase the bending strength, which reaches maximum values when mullite needles join together and give rise to clusters. 
Jorge Martín-Márquez, Jesús Ma. Rincón, Maximina Romero, Effect of microstructure on mechanical properties of porcelain stoneware. Journal of the European Ceramic Society, Volume 30, Issue 15, November 2010, Pages 3063-3069; doi:10.1016/j.jeurceramsoc.2010.07.015

4. Vickers microhardness and Young's modulus show behaviour similar to bending strength curves, which indicates that these properties are governed by the same factors.

5. Fracture toughness is independent of the firing temperature and, therefore, of the physical properties and microstructural features of the fired body.

\section{Acknowledgements}

This research was supported by the Spanish Science and Technology Ministry (Projects MAT2000-1422 and MAT2003-2915). The authors gratefully acknowledge Compañía Europea de Arcillas, S.A. for providing raw materials. The authors thank IRICA from University of Castilla-La Mancha (Spain) for experimental assistance.

\section{References}

1. A. Zoellner, Some chemical and physical properties of porcelain, Sprechsall, 41 (1908), pp. 471-473

2. O.I. Ece, Z. Nakagawa, Bending strength in porcelains, Ceram Int, 28 (2002), pp. 131-140

3. G. Stathis, Effect of firing conditions, filler grain size and quartz content on bending strength and physical properties of sanitaryware porcelain, J Eur Ceram Soc, 24 (2004), pp. 2357-2366

4. S.L. Correia, A.P.N. Oliveira, D. Hotza, A.M. Segadães, Properties of triaxial porcelain bodies: interpretation of statistical modeling, J Am Ceram Soc, 89 (2006), pp. 3356-3365

5. A.De Noni Jr., D. Hotza, V. Cantavellas Soler, E. Sánchez Vilches, Influence of composition on mechanical behaviour of porcelain tile. Part II. Mechanical properties and microscopic residual stress, Mater Sci Eng A, 527 (2010), pp. 1736-1743

6. J.M. Amigó, J.V. Clausell, V. Esteve, J.M. Delgado, M.M. Reventós, L.E. Ochando, et al., X-ray powder diffraction phase analysis and thermomechanical properties of silica and alumina porcelains, $\mathrm{J}$ Eur Ceram Soc, 24 (2004), pp. 75-81

7. L. Mattyasovszky-Zsolnay, Mechanical strength of porcelain, J Am Ceram Soc, 40 (1957), pp. 299306

8. K. Hamano, Y.H. Wu, Z. Nakawaga, M. Hasegawa, Effect of grain size of quartz on mechanical strength of porcelain bodies, J Ceram Soc Jpn, 99 (1991), pp. 149-153

9. G. Stathis, A. Ekonomakou, C.J. Stournaras, C. Ftikos, Effect of firing conditions, filler grain size and quartz content on bending strength and physical properties of sanitaryware porcelain, J Eur Ceram Soc, 24 (2004), pp. 2357-2366

10. S.A.F. Batista, P.F. Messer, R.J. Hand, Fracture toughness of bone china and hard porcelain, $\mathrm{Br}$ Ceram Trans, 100 (2001), pp. 256-259

11. B.O. Aduda, F.W. Nyongesa, Role of aspect ratio in elastic modulus-porosity relationship of triaxial porcelain, Br Ceram Trans, 99 (2000), pp. 206-211

12. R. Pickup, Effect of porosity on Young's modulus of a porcelain, Br Ceram Trans, 96 (1997), pp. 9698

13. C. Zanelli, M. Dondi, C. Guarini, M. Raimondo, I. Roncarati, Influence of strengthening components on industrial mixture of porcelain stoneware tiles, Key Eng Mater, 264-268 (2004), pp. 1491-1494

14. P.M.T. Cavalcante, M. Dondi, G. Ercolani, G. Guarini, C. Melandri, M. Raimondo, et al., The influence of microstructure on the performance of white porcelain stoneware, Ceram Int, 30 (2004), pp. 953-963 
Jorge Martín-Márquez, Jesús Ma. Rincón, Maximina Romero, Effect of microstructure on mechanical properties of porcelain stoneware. Journal of the European Ceramic Society, Volume 30, Issue 15, November 2010, Pages 3063-3069; doi:10.1016/j.jeurceramsoc.2010.07.015

15. M. Dondi, G. Ercolani, C. Melandri, C. Mingazzini, M. Marsigli, The chemical composition of porcelain stoneware tiles and its influence on microstructural and mechanical properties, Interceram, 48 (1999), pp. 75-83

16. L. Carbajal, F. Rubio-Marcos, M.A. Bengochea, J.F. Fernández, Properties related phase evolution in porcelain ceramics, J Eur Ceram Soc, 27 (2007), pp. 4065-4069

17. A.De Noni Jr., D. Hotza, V.E. Cantavella Soler, E. Sánchez Vilches, Effect of quartz particle size on the mechanical behaviour of porcelain tile subjected to different cooling rates, J Eur Ceram Soc, 29 (2009), pp. 1039-1046

18. M. Dondi, G. Guarini, C. Melandri, M. Raimondo, P.M.T. Cavalante, C. Zanelli, Resistance to deep abrasion of porcelain stoneware tiles: key factors, Ind Ceram, 25 (2005), pp. 71-78

19. C. Leonelli, F. Bondioli, P. Veronesi, M. Romagnoli, T. Manfredini, G.C. Pellacani, et al., Enhancing the mechanical properties of porcelain stoneware tiles: a microstructural approach, J Eur Ceram Soc, 21 (2001), pp. 785-793

20. E. Sánchez, M.J. Orts, J. García-Tena, V. Cantavella, Porcelain tile composition effect on phase formation and end products, Am Ceram Soc Bull, 80 (2001), pp. 43-49

21. L. Esposito, A. Salem, A. Tucci, A. Gualtieri, S.H. Jazayeri, The use of nepheline-syenite in a body mix for porcelain stoneware tiles, Ceram Int, 31 (2005), pp. 233-240

22. J. Martín-Márquez, J.Ma. Rincón, M. Romero, Effect of firing temperature on sintering of porcelain stoneware tiles, Ceram Int, 34 (2008), pp. 1867-1873

23. J. Martín-Márquez, A.G. De la Torre, M.A.G. Aranda, J.Ma. Rincón, M. Romero, Evolution with temperature of crystalline and amorphous phases in porcelain stoneware, J Am Ceram Soc, 92 (2009), pp. 229-234

24. J. Martín-Márquez, J.Ma. Rincón, M. Romero, Mullite development on firing in porcelain stoneware bodies, J Eur Ceram Soc, 30 (2010), pp. 1599-1607

25. S. Maity, B.K. Sarkar, Development of high-strength whiteware bodies, J Eur Ceram Soc, 16 (1996), pp. 1083-1088

26. D.N. Boccaccini, A.R. Boccaccini, Dependence of ultrasonic velocity on porosity and pore shape in sintered materials, J Nondestruct Eval, 16 (1997), pp. 187-192 